presentation of campylobacter infection in immunodeficient patients may result in inappropriate treatment.

'Asherson GL, Webster ADG. Diagnosis and treatment of immunodeficiency diseases. Oxford: Blackwell Scientific Publications, 1980.

Pönkä A, Tilvis $R$, Kosunen $U$. Prolonged campylobacter gastroenteritis in patient with hypogammaglobulinaemia. Acta Med Scand 1983;213:159-60.

Ahnen DJ, Brown WR. Campylobacter enteritis in immune-deficient patients. Ann Intern Med 1982;96:187-8.

列

(Accepted 2 May 1984)

Departments of Haematology and Gastroenterology, Whittington Hospital, London N19 5NF

E S GREEN, MA, MRCP, senior house officer

N E PARKER, MRCP, MRCPATH, consultant haematologist

A R GELLERT, $M B$, MRCP, registrar

E R BECK, FRCP, consultant physician

Correspondence to: Dr E S Green, Department of Haematology, Royal Free Hospital, London NW3 2QG.
The results of this study indicate that once the decision has been made to investigate patients with epilepsy, dementia, and non-specific symptoms without neurological signs by computed tomography a skull series should not initially be performed. If it is decided that computed tomography is not initially indicated, or facilities for computed tomography are not easily available, a lateral skull radiograph, plus an anteroposterior radiograph if the pineal gland is calcified, is all that is required.

' Royal College of Radiologists. A study of the utilisation of skull radiography in 9 accident-and-emergency units in the UK Lancet 1980;ii:1234-7.

'Rastogi SC, Barraclough BM. Skull radiology in patients with psychiatric illness.

Br Med $\mathcal{F} 1983 ; 287: 1259$.
${ }^{3}$ Tress BM, Hare WSC. CT in dementia, epilepsy and non-specific neurological symptoms without signs: is there a place for radionuclide scanning ? Med 7 Aust $1979 ; 1: 453-4$.

Bull JWD, Zilkha KJ. Rationalising requests for $x$-ray films in neurology. Br Med $\mathcal{f}$ 1968;iv:569-90.

Cromwell LD, Mack LA, Loop JW. CT Scoutview for skull fractures: substitute for skull films? $A \exists N R$ 1982;3:421-3.

(Accepted 17 May 1984)

University of Melbourne Department of Radiology, Royal Melbourne

Hospital, Victoria 3050, Australia

BRIAN M TRESS, FRCR, FRACR, first assistant

\section{Skull radiography in epilepsy, dementia, and non-specific neurological symptoms}

Despite the development and widespread use of computed tomography skull radiographs continue to be ordered routinely, often as a prelude to computed tomography. Recent reports of studies to evaluate skull radiographs in trauma ${ }^{1}$ and psychiatric illness ${ }^{2}$ contained only limited references to the unique diagnostic information provided by skull radiographs compared with computed tomograms. Our study was designed to determine whether skull radiography could provide any important diagnostic information not available from computed tomograms in patients presenting with epilepsy, dementia, or nonspecific neurological symptoms.

\section{Patients, methods, and results}

During 12 months 367 patients were referred for computed tomography. They had a presumptive diagnosis of epilepsy or dementia or were suffering from headache, vertigo, or blackouts without any focal neurological signs or papilloedema. Those patients who had not had a series of skull radiographs within the preceding week underwent a full four film skull series on the same day as the computed tomography. Computed tomography was performed with an EMI 1010 head scanner. The abnormalities seen in the scans were compared with those detected in the skull radiographs.

Skull radiographs showed abnormalities not seen on computed tomography in 14 of the 367 patients. These consisted of five skull fractures, five cases of sinus disease, and one case each of hyperostosis induced by tumour, signs of raised intracranial pressure, enlarged middle meningeal markings, and craniostenosis. In every case the abnormal skull radiograph finding was seen in the lateral skull radiograph alone.

\section{Comment}

The diagnostic yield achieved by computed tomography in patients presenting with dementia, epilepsy, and non-specific neurological symptoms without signs has been reported previously. ${ }^{3}$ In only 14 patients did the skull radiograph show diagnostic features not shown by computed tomography. Although the enlarged middle meningeal vascular markings and hyperostosis induced by tumour helped confirm the diagnosis of meningioma in two cases, the skull radiograph findings did not actively cause the management of any of the patients to be changed.

Our finding that all the abnormalities were evident in the lateral skull radiograph accords with the findings of Bull and Zilkha. ${ }^{4}$ They recommended that in the absence of physical signs a lateral view of the skull plus an anteroposterior projection to show the position of the pineal gland (if it is shown to be calcified in the lateral projection) is all that is initially required.

Computed tomography performed with modern third and fourth generation scanners is preceded by a computerised radiograph generated by the scanner. The quality of this computerised radiograph is such that in a recent study of computed tomography in trauma it detected 20 of 21 fractures of the skull. ${ }^{5}$

\section{Spontaneous separation of fused labia minora in prepubertal girls}

Labial adhesions or fused labia minora are a common problem in prepubertal girls. They are harmless but must be differentiated from anatomical abnormalities. Commonly they are asymptomatic, though they may be associated with apparent urinary symptoms. Patients are referred to surgical clinics usually because their parents fear an abnormal development of the external genitalia. Occasionally the adhessions are an incidental finding during the course of routine examination. Topical oestrogen cream has been advocated as effective treatment. ${ }^{12} 3$ Alternatively, separation under general anaesthetic, except in very young infants, has been recommended. ${ }^{4}{ }^{5}$ Treatment has been urged for these children in case more dense adherence develops. This study was undertaken to determine whether any intervention is necessary.

\section{Patients, methods, and results}

Over three years 10 girls aged from 10 to 22 months were seen in the outpatient department by one surgical firm and subsequently followed up. Two other girls were lost to follow up. The diagnosis of labial adhesions was the primary reason for attendance in nine; in the tenth diagnosis was an incidental finding at examination. In each case the parents and, when appropriate, the patient were reassured and no further action was taken. The patients were then re-examined at 6,12 , and, if necessary, 18 months.

After six months five of the 10 showed complete and spontaneous separation, four partial separation, and one no change. By 12 months nine cases had resolved, and by 18 months all 10 had resolved completely. Adhesion did not subsequently recur in any of the patients.

\section{Comment}

Treatment for fused labia minora with local oestrogen cream has an incidence of success of about $90 \%^{12}$ and was recently stated to be the treatment of choice. ${ }^{3}$ Side effects, however, have been reported. Aribarg found that reversible vulval pigmentation developed in all patients, one also developing vulval erythema, and adhesion recurred in one girl. ${ }^{2}$ Capraro and Greenberg noticed a small incidence of breast enlargement and tenderness. ${ }^{1}$ We have seen a child in whom adhesions recurred after the application of oestrogen cream had been stopped. Moreover, this treatment requires good compliance by patient and parent and may be resented by the child.

Surgical separation is long established ${ }^{4}$ and still has its advocates. ${ }^{5}$ Unless, however, patients undergo surgery when they are only a few months old, they have to be anaesthetised and may suffer undue distress. The stress of admitting a child to hospital and the potential risk of a general anaesthetic led us to undertake this study. Furthermore, the incidence of recurrent adhesions has been reported to be as high as $20 \%{ }^{4}$

Conservative management in our series led to an incidence of spontaneous separation of $100 \%$, albeit over 18 months, though half 